Pates, J., Karageorghis, C. I., Fryer, R., \& Maynard, I. (2003). Effects of asynchronous music on flow states and shooting performance among netball players. Psychology of Sport and Exercise, 4, 415-427.

\title{
EFFECTS OF ASYNCHRONOUS MUSIC ON FLOW STATES AND SHOOTING PERFORMANCE AMONG NETBALL PLAYERS
}

\author{
John Pates ${ }^{1}$, Costas I. Karageorghis ${ }^{2}$, Robert Fryer $^{1}$, and Ian Maynard ${ }^{1}$ \\ ${ }^{1}$ Sheffield Hallam University \\ ${ }^{2}$ Brunel University, West London
}

Final draft submitted: 7 August 2002

Correspondence address: Costas Karageorghis, Department of Sport Sciences,

Brunel University, West London, Uxbridge Campus, Uxbridge, Middlesex UB8 3PH, England, U.K.

Tel: 01895-274 000 Ext. 5796

Fax: 01895-816 341

Email: costas.karageorghis@brunel.ac.uk 
EFFECTS OF ASYNCHRONOUS MUSIC ON FLOW STATES AND SHOOTING PERFORMANCE AMONG NETBALL PLAYERS

Final draft submitted: 7 August 2002 


\begin{abstract}
Objectives: To examine the effects of self-selected asynchronous (background) music on flow and netball shooting performance in three netball players. Based on the research of Karageorghis and Terry (1999) it was hypothesized that music would promote flow and thus, would have a positive impact on netball shooting performance.

Design: An idiographic single-subject multiple baselines across-subjects design was employed (Wollman, 1986). The rationale for using this design centred upon the work of Patrick and Hrycaiko (1998) who indicated that single-subject designs were the most appropriate methodology for applied research.

Methods: The participants comprised three collegiate netball players who were asked to complete 11 performance trials. Each trial involved taking 12 shots from lines located at three shooting positions. After each performance trial, flow and the internal experience of each player were assessed using the Flow State Scale (Jackson \& Marsh, 1996) and Practical Assessment Questionnaire. Participants received the intervention of asynchronous music with the length of pre-intervention baseline increasing for each succeeding player. Results: The results revealed that two of the participants experienced an increase in the perception of flow while all three participants improved their netball shooting performance. In addition, participants indicated that the intervention helped them to control both the emotions and cognitions that impacted upon their performance.

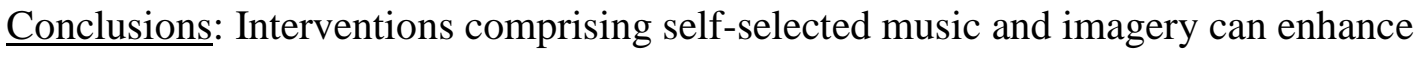
athletic performance by triggering emotions and cognitions associated with flow.
\end{abstract}

Key words: Optimal experience, intervention, emotional control. 


\section{Effects of asynchronous music on flow states and shooting performance among netball players}

The sport psychology literature contains an abundance of anecdotal and qualitative evidence suggesting that optimal performance depends, in part, on the intensity and experience of a mental state described as flow (e.g., Jackson \& Csikszentmihalyi, 1999).

\section{Introduction}

The main proponent of flow, Csikszentmihalyi $(1975,1990)$ explained that it represents an optimal psychological state that is characterised by a near perfect match between the challenge imposed by a particular situation and the skills that the performer brings to it. During flow, one is totally absorbed in the task leading to optimal physical and mental functioning. It is seen as an altered state of awareness in which one feels deeply involved in the activity and where mind and body operate harmoniously. Flow represents the apotheosis of intrinsic motivation; ostensibly, the activity is enjoyable in its own right and not engaged in for the derivation of external rewards and benefits (Vlachopoulos, Karageorghis, \& Terry, 2000).

Although the use of qualitative methods provides rich accounts of the flow experience, distinct limitations such as the retrospective nature of interviews and the interpretative bias of the experimenter mean that quantitative methods for assessing flow are equally useful to researchers. To this end, Jackson and Marsh (1996) filled a void in the literature by developing the Flow State Scale (FSS), a self-report instrument that provides both a global measure of the flow experience and a score for each of the nine subcomponents of the flow experience.

The development of the FSS enabled Karageorghis and Terry (1999) to examine the relationship between flow and the motivational qualities of music. In their study, 1231 aerobic dance exercise participants were asked to rate their experience of flow after the 
completion of an aerobic dance exercise class. They were also asked to rate the motivational qualities of the music programme using the Brunel Music Rating Inventory, an instrument that was subsequently published by Karageorghis, Terry, and Lane in 1999. The results revealed a significant association between ratings of the motivational qualities of music and perceptions of flow. This study was correlational in nature and thus, does not allow the reader to infer causality. However, the findings may have important consequences for the applied sport psychologist given the implications for the promotion of flow experience, which may, in turn, promote superior sporting performance.

Unfortunately, research supporting this conjecture is not currently available. Nevertheless, evidence for the positive effect of music on performance can be gauged from a number of sources. For example, Ferguson, Carbonneau, and Chambliss (1994) demonstrated that karateka (karate players) attained superior performances with the use of asynchronous (background) music during performance. Likewise, performance improvements were observed in treadmill running tasks under conditions of asynchronous music (Copeland \& Franks, 1991; Lee, 1989). Additionally, Anshel and Marisi (1978) and Michel and Wanner (1975) provided evidence for improved work output under conditions in which music was synchronised with physical tasks (synchronous music). Studies that have investigated the stimulative or energising effects of music have also noted benefits in the performance of physical tasks (Karageorghis, Drew, \& Terry, 1996; Templin \& Vernacchia, 1995).

The influence of music in the promotion of flow state in an exercise context has been the subject of recent research interest (Karageorghis, Vlachopoulos, \& Terry, 2000), with the prevailing view being that carefully selected music may promote flow. Careful selection of music entails consideration of participants' ages, socio-cultural background, and preferences as well as the task that the music is intended to accompany (see Lucaccini \& Kreit, 1972; Karageorghis \& Terry, 1997; Karageorghis et al., 1999). One mechanism 
through which music may impact on flow is by enhancing pre-performance mood. Indeed, in a recent review, Terry (in press) presented a strong case for the mood-enhancing effects of music in a sport context. Further, Jackson (1992) reported that pre-performance mood was a key antecedent of flow among elite figure skaters.

Karageorghis and Deeth (2002) assessed the effects of asynchronous (background) motivational music and oudeterous (defined as neither motivational nor demotivational) music on perceptions of flow during an endurance shuttle running task. Significantly, this was the first study that controlled for the possible confound of variability in preperformance mood (cf. Jackson, 1992; Terry, in press). Results from the repeated measures design indicated that the motivating music condition engendered significantly higher flow scores, as measured by the FSS, when compared to the no-music control condition.

The strong link between music and changes in motor behaviour and cognitive states may be explained in terms of Norman and Shallice's (1986) cognitive model of behavioural control. The model proposes that the cognitive system is comprised of a large, distributed set of specialised processing systems under the guidance of a two-tiered cognitive control system. In routine situations, behaviours may be controlled exclusively by the operation of low-level cognitive control structures or schemata, which are triggered by cues in the internal and external environment in accordance with a contention scheduling mechanism, which operates automatically without consuming attentional resources. This low-level of control is considered to be an automatic process, requiring neither attention/awareness nor volition for its operation.

When an individual is faced with novel demands, a second higher-level system can intervene to initiate behaviour via the active excitation or inhibition of schemata at the level of contention scheduling. This central cognitive structure, the supervisory attention 
system, is both a monitoring and a controlling system. This high-level control structure is not needed to select lower level schemata when processing demands are routine.

In the case of routine processing, environmental triggers and the competitive excitation and inhibition between schemata (contention scheduling) are sufficient to control behaviour. Ostensibly, the supervisory attention system intervenes only when existing schemata are unable or unsuitable to meet processing demands, as in the case of a novel situation or when a habitual response is no longer appropriate. However, the degree to which the supervisory system will be used in the control of behaviour is a function of both situational and dispositional factors, including the availability of attention resources moderated by current processing demands, the perceived importance or difficulty of a situation, or other variables such as anxiety and fatigue.

It is possible that music may engender a state in which the supervisory system of control is inhibited, leading to an individual's over-reliance on situational cues to determine subsequent behaviour. Under these non-analytical conditions, athletic performance is likely to improve and an athlete's perception of their behaviour may be altered resulting in a mindset that is characterised by flow. The implication is that flow states and the states engendered by certain kinds of music have similarities. The findings of Karageorghis and Terry (1999) supported this notion insofar as music programmes that scored highly for their motivational qualities were associated with a flow experience.

The Norman and Shallice (1986) cognitive model of behavioural control represents a plausible cognitive theory of the music-flow-performance relationship. While retaining a cognitive premise, it acknowledges how environmental factors might play an important role in shaping the flow experience. This encompasses the posits of Csikszentmihalyi's (1975) model of the flow experience that describes flow as the balance between skill (action capabilities) and challenge (action opportunities). Moreover, it is a respected model 
of behavioural control developed within cognitive psychology and, on this basis, offers testable predictions with which to assess its validity.

Beyond the controlled experimental or quasi-experimental studies of research involving the effects of music on sporting performance, the employment of ecologically valid designs is extremely limited. Consequently, in the present study, an attempt was made to build upon the extant literature through examining the applicability of music to shooting performance in netball players. A secondary purpose of this study was to examine the effects of music on players' experience of flow. It was anticipated that the effects of music would be optimised through asking players to self-select music that they associated with memories of their most outstanding athletic performances. This decision served to exploit the components of motivational music (see Karageorghis et al., 1999). More specifically, the extra-musical associations that players had with their self-selected music were expected to rouse them towards optimal psychological state and superior performance.

A single-subject design has several advantages over a group design. First, there are often difficulties obtaining large samples from athletic populations. In single-subject designs only small sample sizes are needed. Second, single-subject designs have participants acting as there own controls. This means that all participants receive an intervention that may be found to be effective. Third, single-subject designs allow small but consistent changes in behaviour to be observed. For elite athletes, small changes are often considered to be extremely valuable. For these reasons, some applied sport psychologists (see Patrick \& Hrycaiko, 1998) deem this methodology to be the most advantageous for applied research. Based on the recommendations of Wollman (1986), a single-subject multiple baseline, across-subjects design, coupled with a procedure that 
monitored flow states and the internal experience of each player, was implemented to evaluate the effects of self-selected music.

\section{Method}

\section{Participants}

The volunteer participants comprised three members of a female collegiate netball squad located in the north of England. They were in the age range 19-21 years $(\mathrm{M}$ age $=$ 20.00 years, $\mathrm{SD}=1.00$ years). Participants were informed of the basic nature of the research and were requested to sign an informed consent form prior to engaging in the study.

The participants were regular 'starting' players with at least eight years' competitive experience in netball. All three players had played in the 'primary shooter' position at some point in their careers. The participants reported no previous experience with the use of music in the context of netball.

\section{Experimental Design}

A single-subject multiple baselines across individuals design was implemented to examine the effects of music intervention on flow states and shooting performance. This type of design allows participants to serve as their own control (Barlow \& Hersen, 1984; Hrycaiko \& Martin, 1996). The design required the observation of baseline performance and treatment phases for each of the participants. The baselines of each player had a different length. The intervention was introduced when a stable baseline or a trend in the opposite direction of the change anticipated became apparent for each of the participants. A sequential application of the music was applied until all participants received the intervention. Using the multiple baseline to sequentially apply the independent variable across multiple subjects provides more information about the effectiveness of the independent variable and its generality. 


\section{Dependent variables}

\section{Shooting performance}

Shooting was selected as a criterion task for two reasons. First, participants were very familiar with the technique, which served to minimise learning effects (Thomas \& Nelson, 2001, pp. 314-315) and second, it reflected a key component of their performance in the sport of netball. The task required the participants to take 12 shots from lines located at three positions. Specifically, four shots were taken from the left and four from the right side of the netball posts from a distance of $3.2 \mathrm{~m}$ and at an angle of $45^{\circ}$ from the back line. The remaining four shots were taken directly in front of the netball posts, again at a distance of $3.2 \mathrm{~m}$. These points were selected to make the shooting performance applicable to a match situation and hence, maintain the ecological validity of the study. The experimenter recorded each attempt using the following scoring system: 0 for a complete miss; 1 for the ball hitting the rim and not going through the net; 2 for the ball hitting the rim and going through the net; and 3 for a 'clean' basket. Performance was measured by summating the scores for the 12 shots. Comparing the judgements of two independent observers assessed the reliability of the performance observations. These observers took concurrent measures of the target behaviour. The reliability assessment took place prior to the study and resulted in a Spearman's rank-order correlation coefficient of 1.00 for the scores of the two independent observers.

Flow analysis

In addition to the performance data, the degree to which participants experienced flow was assessed using the Flow State Scale (Jackson \& Marsh, 1996). This 36-item instrument provides a quantitative measure of the nine dimensions of flow outlined by Csikszentmihalyi (1990). The dimensions measured by this instrument are: Challenge-skill balance (e.g., "I was challenged but I believed my skills would allow me to meet the 
challenge"), action-awareness merging (e.g., "I made the correct movements without thinking about trying to do so"), clear goals (e.g., "I knew clearly what I wanted to do"), unambiguous feedback (e.g., "It was really clear to me that I was doing well”), concentration on task at hand (e.g., "My attention was focused entirely on what I was doing"), sense of control (e.g., "I felt in control of what I was doing"), loss of selfconsciousness (e.g., "I was not concerned with what others may have been thinking of me"), transformation of time (e.g., "It felt like time stopped when I was performing"), and autotelic experience (e.g., "I found the experience extremely rewarding"). The FSS scores were used to determine the extent to which the participants experienced flow during each trial. Respondents indicated the extent to which they agreed with each item on a 5-point Likert-type scale anchored by 1 (strongly disagree) and 5 (strongly agree). A global measure of flow was preferred in this investigation given Jackson's (2000) contention that multi-factor approaches tend to reveal incomplete information about the total flow experience. However, it is acknowledged that single dimension scores received stronger psychometric support in Jackson's study. Alphas for the nine FSS scales range from .72 to .91 (see Jackson, Kimiecik, Ford, \& Marsh, 1998).

\section{Intervention procedure}

Immediately following the completion of the final trial of baseline testing, an explanation of flow state, as described by Jackson and Marsh (1996), was given to each participant. They were then instructed to recall both the images and feelings they associated with their experiences of flow in sport. The instructions further directed participants to rehearse an image of flow and to imagine performing from an internal perspective. After this period of instruction, players were asked to select a single track of music, from their own compact disc collection that facilitated feelings similar to their flow experiences. Participant 1 chose "Unfinished Symphony" by Massive Attack, Participant 2 
chose "TwoTribes" by Frankie Goes to Hollywood, and Participant 3 chose "Makes Me Love You" by Eclipse. Specifically, player self-selection was employed to overcome the numerous problems associated with externally imposed selections that have blighted past experimental work (see Karageorghis \& Terry, 1997, for review). Further, self-selection was used to enhance the participants' sense of autonomy. Given that autonomy is one of the psychological needs underlying intrinsic motivation (Deci \& Ryan, 1985; Ryan \& Deci, 2000), self-selection was expected to promote flow -- the apotheosis of intrinsic motivation.

Following the selection of the music, each participant was taken to a room and played the track they had chosen. The selection of the music was considered complete when participants reported feelings they associated with their experiences of flow could be experienced through listening to the music they had chosen. It is noteworthy that all three participants recognised that the characteristics of flow were present during their most outstanding performances. Following the selection of music, the players began the intervention phase of the design. During this phase, the selected music was played as the participants attempted a shot. After each performance trial, flow and the internal experience of each player were assessed using the FSS and a practical assessment questionnaire. Each performance trial lasted approximately 10 minutes.

\section{Practical Assessment Questionnaire}

In order to provide information about the effectiveness of the intervention, each of the participants completed a practical assessment questionnaire adapted from Kazdin, (1992) and Kendall, Hrycaiko, Martin, and Kendall (1990). Specifically, participants were asked the following questions: "How did you feel during the performance?", "What were you thinking during the performance?", "Were there any outside thoughts distracting you?", "Did you experience any problems?", "Were you satisfied with the results 
following the intervention?", "Were the procedures acceptable to you?", "What was the effect of the intervention?", "What were your general beliefs about your performance?", and "How much effort did you put into today's performance?"

Following the completion of the study, the participants were administered a social validation questionnaire recommended by Hrycaiko and Martin (1996). The questionnaire was designed to provide information concerning the importance of the study and the effectiveness of the intervention. Specifically, the participants were asked the following questions: "Did you perceive the shooting task to be important?", "Were the procedures of the study acceptable?", and "Are you satisfied with the results?" (see Hrycaiko \& Martin, 1996).

\section{Treatment of data}

The performance scores obtained from each participant were plotted to indicate the accuracy of their attempts. Through visual inspection of the data, the researchers used the following criteria to establish the occurrence of a significant experimental effect: a) When baseline performance was stable or in the direction opposite to that predicted for the effects of treatment; b) the greater the number of times that an effect was replicated both within and across subjects; c) the smaller the number of overlapping data points between baseline and treatment phases; d) the sooner the effect occurs following the introduction of the treatment; and e) the larger the size of the effect in comparison to baseline (Hrycaiko \& Martin, 1996). Collectively, these are recognised as the 'gold standard' criteria used to establish an effect in single-subject designs. If all or most of these criteria are met, this is a strong indication of an effect (Hrycaiko \& Martin, 1996).

\section{Procedural reliability assessment}

To ensure that participants received the same information when they were choosing the music, the following standard protocol was used: (a) Thorough explanation of the flow 
phenomenon; (b) mental imagery of a performance during which they had experienced flow; (c) note the emotions and cognitions they experienced during flow; (d) select a piece of music that triggers similar emotions and cognitions experienced during flow; (e) go into a quiet room and play the selected music; (f) have participants access their flow state utilising the music; (g) ask participants if they have any questions; (h) copy questions down and answer them; and (i) check understanding with participants. Verification that all aspects of the standard protocol were applied consistently was obtained from a trained observer.

\section{Results}

The shooting performance data for each participant are presented in Fig 1. For each of the three participants, the music intervention led to an increase in performance accuracy, with Participant 1 displaying the largest improvement. This finding suggests that the music intervention caused a consistent improvement in shooting performance. Specifically, Participant 1 improved from a mean of 20 during the first baseline, to a mean of 26 during the intervention phase. Participant 2 increased from a mean of 18 to 24, and Participant 3 from 18 to 23 . The effect of the intervention was immediate with only one overlapping data point between the baseline phase and intervention phase.

Insert Figure 1 about here

The results of the flow data for each participant are presented in Figure 2. For each of the three participants, the music intervention resulted in an improved score. This pattern of results suggests the intervention increased the degree to which participants experienced flow. Specifically, Participant 2 displayed the largest increase in flow from a mean score of 109 during the baseline to a mean of 143 during the intervention. Participant 3 improved 
from a mean of 100 during the baseline to a mean of 129 during the intervention phase. For Participants 2 and 3, the effect of the intervention was immediate with no overlapping data points between the baseline phase and intervention phase. Participant 1's mean score of 102 during baseline improved during the intervention to a score of 112 . However, the effect was not immediate. There were also two overlapping data points between the intervention and baseline.

Insert Figure 2 about here

\section{Practical assessment data}

On completion of the netball-shooting task, participants were asked to respond to a practical assessment questionnaire. All participants indicated that, during the intervention phase, they had made a sustained effort throughout the trials. Further, they indicated that the intervention had improved their performance. Participants had also felt more relaxed, calm, composed, in control, and confident when compared to the baseline phase. For example, Participant 1 indicated that during the intervention phase, she had felt more relaxed and confident, and that her shooting was more controlled and had a rhythm: "shooting was easy ...I could not miss ...I could will the ball to go where I wanted it to go, this made me feel confident and great. I had my rhythm and it was really fun". Moreover, she reported that she had no thoughts about her technique and had high levels of concentration, "I thought of nothing ...I had complete concentration".

Additionally, Participant 2 also indicated she had experienced reduced concerns about the outcome of her performance, "my shot was automatic ...I forgot about technique and just relied upon my increased confidence". Participant 2 also indicated that during the intervention phase, she had felt more relaxed and her shooting had more rhythm, "my 
shooting was easy ...I had great rhythm". Moreover, she reported that she had felt intense relaxation in her body and the music had changed her emotions and level of concentration "My body was very relaxed ...I stopped thinking about what was around me ...I had complete concentration and focus ...the music made me high and kept me in the zone".

Similar responses were provided by Participant 3: "My mind went blank and everything became automatic ...I just knew the shots were going to go in". Participant 3 also indicated that she felt more in control of her shooting and had improved her consistency and control of the ball: "I thought I could shoot the ball from anywhere ...I was surprised to see the ball going in so many times". She also stressed that she felt the intervention had changed her feelings and mood making her feel more positive and the task more fun. "I really enjoyed shooting to the music ...I had so much fun ...I felt positive and energised".

Upon completing the study, each player responded to a social validation questionnaire. They all reported being satisfied with the results of the intervention and recognised the intervention had made them more consistent shooters.

\section{Discussion}

The aim of the study was to investigate the effect that music has upon flow states and shooting performance among collegiate netball players. All three participants exhibited improvements in performance during the intervention. These results suggest that music may be an effective tool for improving performance in netball players. This supports previous research that found music to be an effective tool for improving athletic performance (Copeland \& Franks, 1991; Ferguson et al., 1994; Karageorghis et al., 1996; Lee, 1989). Two of the three participants also showed increases in flow during the intervention, which suggests that in some players, flow may be induced using music interventions. However, it should be noted that the observed changes in flow were not 
always consistent with changes in performance. Indeed, during the intervention, Participant 1 's flow scores did not change from the baseline to intervention. This finding is interesting since it is consistent with Jackson and Csikszentmihalyi's (1999) observation that high performance can occur in the absence of high flow.

The results from the practical assessment questionnaire also provided some interesting findings. For example, Participant 1 reported that she had experienced a number of peak performance characteristics during the intervention phase such as relaxation, confidence, fun, enhanced concentration, and movements that felt automatic and rhythmical. Participants 2 and 3 also reported a number of changes in their emotions and perception during the intervention. Specifically, Participant 2 indicated that the intervention had increased her rhythm, concentration, and level of positive emotions such as relaxation. She also indicated the music improved her ability to stay focused and in the zone. Similarly, Participant 3 experienced more energy, enjoyment, and fun as well as improved control and consistency in shooting during the intervention phase of the study. Such findings support the tenets of Norman and Shallice's (1986) cognitive model of behavioural control insofar as music appears to engender a state in which the supervisory system of control is inhibited. This results in positive perceptions of the self with associated improvements in motor performance.

The qualitative data suggest that music not only improves performance and increases feelings associated with flow but may also be used to help athletes cope with competition anxiety and to improve their self-confidence. These results are clearly relevant for applied sport psychologists. It should be cautioned that the mechanism by which music interventions increase performance and the experience of flow is not known. However, it is possible that music facilitates flow and superior performance by triggering emotions that are important antecedents of the flow experience. 
Another important aspect of this study was that the single-subject multiple baselines across-subjects design enabled the authors to be more confident that the change in flow and performance scores were produced by the intervention and not an uncontrolled or extraneous variable. A favourable social validation assessment and the qualitative information provided further support for the intervention effect.

In terms of limitations in the present study, it should be noted that Jackson (2000) questioned both the use of retrospective self-reports as a measure of flow and the reduction of subjective experiences into quantifiable terms. Gathering information using a multimethod approach may yield a more accurate understanding of flow experienced by sportspeople and should be considered by future researchers.

A further limitation of the study is that an athlete's memory of their best and most outstanding performances may be associated with other experiences and emotions not measured by Jackson and Marsh's (1996) flow state scale (see Hanin, 2000). Indeed, the sport psychology literature clearly indicates at least three different constructs underlying successful athletic performance. The first is flow (Csikszentmihalyi, 1975; Furlong, 1976), defined as an intrinsically enjoyable experience. The second is peak performance (Garfield \& Benett, 1984; Privette, 1983; Privette \& Landsman, 1983), defined as an episode of superior functioning, and the third is, peak experience (Maslow, 1971), defined as an intense and highly valued moment. Ravizza (1977) and Privette (1983) have argued that in a given situation individuals may experience more than one of these phenomena. A comparative analysis of these phenomena (Privette, 1983) suggested that they share many of the same qualities, including absorption, involvement, joy, valuing, self-identity, responsibility, spontaneity, freedom, awareness of power, lost time and space, and temporality. 
The evidence would suggest that the phenomena are interrelated, so that under certain circumstances, the experience of one phenomenon may trigger a second and even a third (Jackson \& Roberts, 1992; Privette, 1983; Privette \& Bundrick, 1991, 1997). For this reason Grove and Lewis (1996) have indicated that these experiences can be collectively labelled "flow" states. On the basis of such evidence, the authors felt that measurement of flow was justifiable.

There remains a possibility, of course, that the improvements in both performance and cognitive states are an artefact of participant and experimenter bias. Indeed, neither the participants nor experimenter were blind to the study purpose and so, experimenter expectations or the demand characteristics of the experiment had the potential to influence results. There also remains an issue of a possible Hawthorne effect, that is, the change in performance that occurs merely as a function of being in an investigation (Drew, 1976). Scrutiny of performers in a single-subject experimental design might heighten this effect. However, Drew (1976) observed that the effect tends to decline as the participants become acclimatised, so the extended length of the single-subject study may have circumvented this potential confound. An additional consideration is that completion of the Flow State Scale may have influenced responses to the practical assessment questionnaire. However, given the nature of the design and the likelihood of losing valuable information with the insertion of a time gap between these two retrospective measures, it was decided that they should be administered concurrently.

A further limitation of the present study is that the experiment may not generalise to game situations. Specifically, during competition, it is rare to attempt shots without the pressure imposed by an opponent or time. Performing the task under experimental rather than competitive conditions detracts somewhat from the ecological validity of our findings. It should also be noted that the use of music interventions is limited by the rules of 
governing bodies of sport. In many competitive situations it is logistically very difficult to incorporate music. However, our results suggest opportunities to use music should be sought to maximise the performance of sports performers. For example, in the sport of netball, music could be used during training, during the pre-match routine, during timeouts or half-time intervals.

In summary, the present findings suggest that a music intervention may enhance performance and trigger emotions and cognitions associated with flow. Further study is required to enable music-related interventions to be accepted by the sports science community on the basis of strong empirical evidence. Specifically, now that the benefits of music have been repeatedly demonstrated in laboratory settings, more ecologically valid and group-based research methods would serve to bolster the knowledge base. 


\section{References}

Anshel, M. H., \& Marisi, D. Q. (1978). Effects of music and rhythm on physical performance. Research Quarterly, 49, 109-113.

Barlow, D. H., \& Hersen, M. (1984). Single case experimental designs: Strategies for studying behavior change (2nd ed.). New York: Pergamon Press.

Copeland, B. L., \& Franks, B. D. (1991). Effects of types and intensities of background music on treadmill endurance. The Journal of Sports Medicine and Physical Fitness, 15, 100-103.

Csikszentmihalyi, M. (1975). Beyond boredom and anxiety. San Francisco: Jossey Bass.

Csikszentmihalyi, M. (1990). Flow: The psychology of optimal experience. New York: Harper \& Row.

Drew, C. J. (1976). Introduction to designing and conducting research. St. Louis: C.V. Mosby.

Ferguson, A. R. Carbonneau, M. R., \& Chambliss, C. (1994). Effects of positive and negative music on performance of a karate drill. Perceptual and Motor Skills, 78, $1217-1218$.

Furlong, V. (1976). Interaction sets in the classroom: Towards a study of pupil knowledge. In M. Hammersley \& P. Woods (Eds.), The process of schooling (pp. 160-170). London: Routledge \& Kegan Paul.

Garfield, C. A., \& Benett, H. L. (1984). Peak performance: Mental training techniques of the world's greatest athletes. Los Angeles: Jeremy Tarcher.

Grove, J. R., \& Lewis, M. A. E. (1996). Hypnotic susceptibility and the attainment of flow states during exercise. Journal of Sport Psychology, 18, 380-391.

Hanin, Y. L. (2000). Emotions in sport. Champaign, IL: Human Kinetics. 
Hrycaiko, D. W., \& Martin, G. L. (1996). Applied research studies with single-subject designs: Why so few? Journal of Applied Sport Psychology, 8, 183-199.

Jackson, S. A. (1992). Athletes in flow: A qualitative investigation into flow state in elite figure skaters. Journal of Applied Sport Psychology, 4, 161-180.

Jackson, S. A. (2000). Joy, fun, and flow state in sport (pp. 135-155). In Y. Hanin (Ed.), Emotions in sport. Champaign, IL: Human Kinetics.

Jackson, S. A., \& Csikszentmihalyi, M. (1999). Flow in sports: The keys to optimal experiences and performances. Champaign, IL: Human Kinetics.

Jackson, S. A., \& Marsh, H. W. (1996). Development and validation of a scale to measure optimal experience: The Flow State Scale. Journal of Sport \& Exercise Psychology, $18,17-35$.

Jackson, S. A., Kimiecik, J. C., Ford, S., \& Marsh, H. W. (1998). Psychological correlates of flow in sport. Journal of Sport \& Exercise Psychology, 4, 358-378.

Jackson, S. A., \& Roberts, G. C. (1992). Positive performance states of athletes: towards a conceptual understanding of peak performance. The Sport Psychologist, 6, 156171.

Karageorghis, C. I., \& Deeth, I. P. (2002). Effects of asynchronous motivational and oudeterous music on perceptions of flow [Abstract]. Journal of Sports Sciences, 20, 66-67.

Karageorghis, C. I., Drew, K. M., \& Terry, P. C. (1996). Effects of pretest stimulative and sedative music on grip strength. Perceptual and Motor Skills, 83, 1347-1352.

Karageorghis, C. I., \& Terry, P. C. (1997). The psychophysical effects of music in sport and exercise: A review. Journal of Sport Behavior, 20, 54-68.

Karageorghis, C. I., \& Terry, P. C. (1999). Criterion validity of the Brunel Music Rating Inventory [Abstract], Journal of Sports Sciences, 17, 61. 
Karageorghis, C. I., Terry, P. C., \& Lane, A. M. (1999). Development and initial validation of an instrument to assess the motivational qualities of music in exercise and sport: The Brunel Music Rating Inventory. Journal of Sports Sciences, 17, 713-724.

Karageorghis, C. I., Vlachopoulos, S. P., \& Terry, P. C. (2000). Modelling the relationship between exercise-induced feeling states and flow. European Physical Education Review, 6, 230-248.

Kazdin, A. E. (1992). Research design in clinical psychology. New York: Macmillan.

Kendall, G., Hrycaiko, D., Martin, G. L., \& Kendall, T. (1990). The effects of an imagery rehearsal, relaxation, and self-talk package on basketball game performance. Journal of Sport \& Exercise Psychology, 12, 157-166.

Lee, K. P. (1989). The effects of musical tempos [sic.] on psychophysical responding during sub-maximal treadmill running (Master's thesis, Pennsylvania State University, 1987). Microform Publications, University of Oregon, Eugene, OR. (University Microfiche No.UNIVORE: U089205).

Lucaccini, L. F., \& Kreit, L. H. (1972). Music. In W. P. Morgan (Ed.), Ergogenic aids in muscular performance (pp. 235-262). New York, NY: Academic Press.

Maslow, A. H. (1971). The farther reaches of human nature. New York: Arkana/Penguin Books.

Michel, W., \& Wanner, H. U. (1975). Einfuss der musik auf die sportliche leistung [Effect of music on sports performance]. Schweizerische Zeitschrift für Sportmedizin, 23, 141-159.

Norman, D. A., \& Shallice, T. (1986). Attention to action: Willed and automatic control of behaviour. In R.J. Davidson, G.E. Schwartz and D. Shapiro (Eds.) Consciousness and self-regulation: Advances in research and theory (pp. 1-18). New York: Plenum. 
Patrick, T. D., \& Hrycaiko, D. W. (1998). Effects of a mental training package on an endurance performance. The Sport Psychologist, 12, 283-299.

Privette, G. (1983). Peak experience, peak performance, and flow: A comparative analysis of positive human experiences. Journal of Personality and Social Psychology, 6, $1361-1368$.

Privette, G., \& Bundrick, C. M. (1991). Peak experience, peak performance, and flow: Correspondence of personal descriptions and theoretical constructs. Journal of Social Behavior and Personality, 6, 169-188.

Privette, G., \& Bundrick, C. M. (1997). Psychological processes of peak, average, and failing performance in sport. International Journal of Sport Psychology, 28, 323334.

Privette, G., \& Landsman, T. (1983). Factor analysis of peal performance: The full use of potential. Journal of Personality and Social Psychology, 44, 195-200.

Ravizza, K. Peak experiences in sport. Journal of Humanistic Psychology, 17, 35-40.

Ryan, R. M., \& Deci, E. L. (2000). Self-Determination Theory and the facilitation of intrinsic motivation, social development, and well-being. American Psychologist, $55,68-78$.

Templin, D. P., \& Vernacchia, R. A. (1995). The effects of highlight music videotapes upon the game performance of intercollegiate basketball players. The Sport Psychologist, 9, 41-50.

Terry, P. C. (in press). Mood and emotions in sport. In T. Morris and J. Summers (Eds.). Sport psychology: Theory, applications and issues (2nd ed). Brisbane: Wiley.

Thomas, J. R., \& Nelson, J. K. (2001). Research methods in physical activity (3rd ed). Champaign, IL: Human Kinetics. 
Vlachopoulos, S. P., Karageorghis, C. I., \& Terry, P. C. (2000). Hierarchical confirmatory factor analysis of the Flow State Scale in exercise. Journal of Sports Sciences, 18, 815-823.

Wollman, N. (1986). Research on imagery and motor performance: Three methodological suggestions. Journal of Sport Psychology, 8, 135-138. 


\section{Figure Captions}

Fig. 1. Performance accuracy for each participant across each trial.

Note. The scores plotted on the left-hand side of the vertical line represent baseline measures and those on the right-hand side represent intervention measures.

Fig. 2. Flow State Scale scores for each participant on each trial.

Note. The scores plotted on the left-hand side of the vertical line represent baseline measures and those on the right-hand side represent intervention measures. 
Participant 1

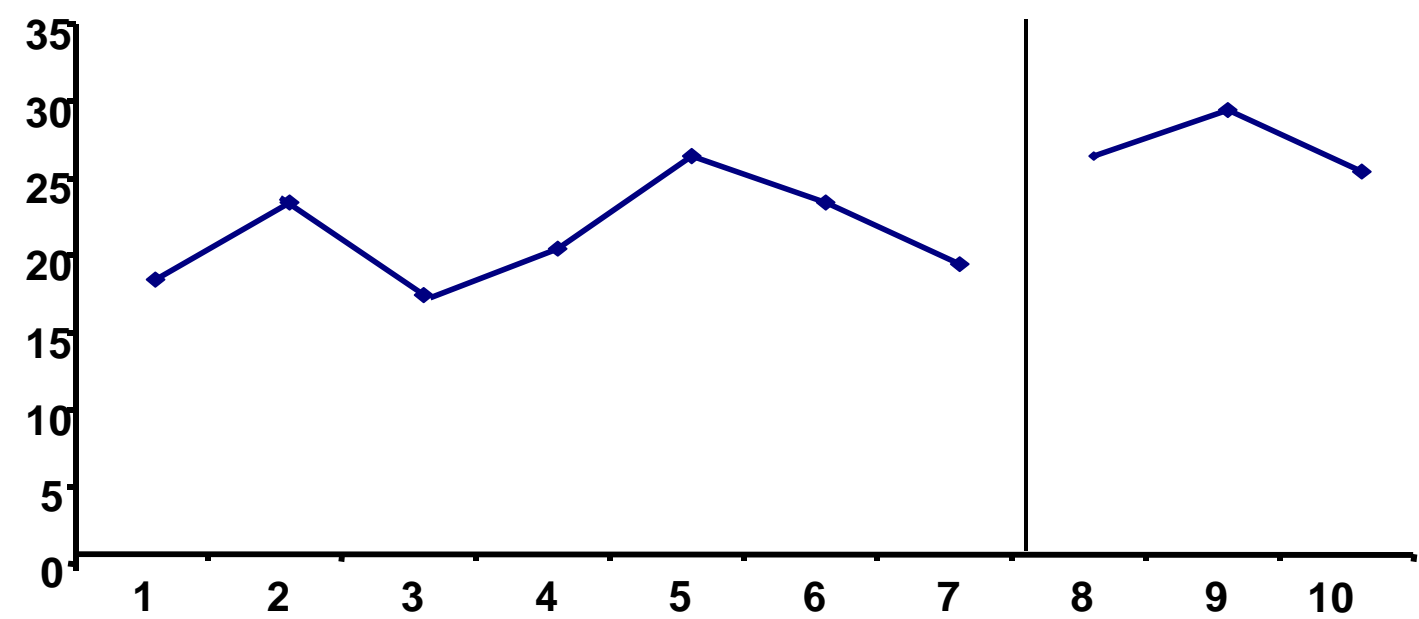

Participant 2

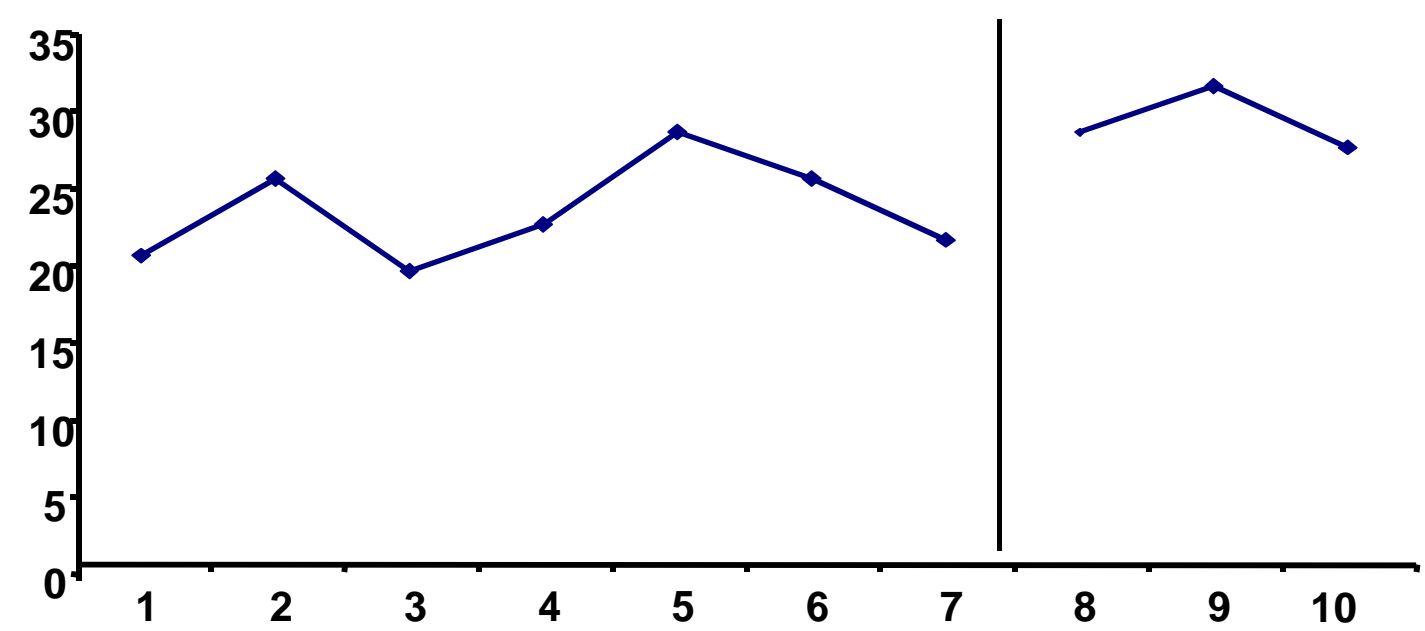

Participant 3

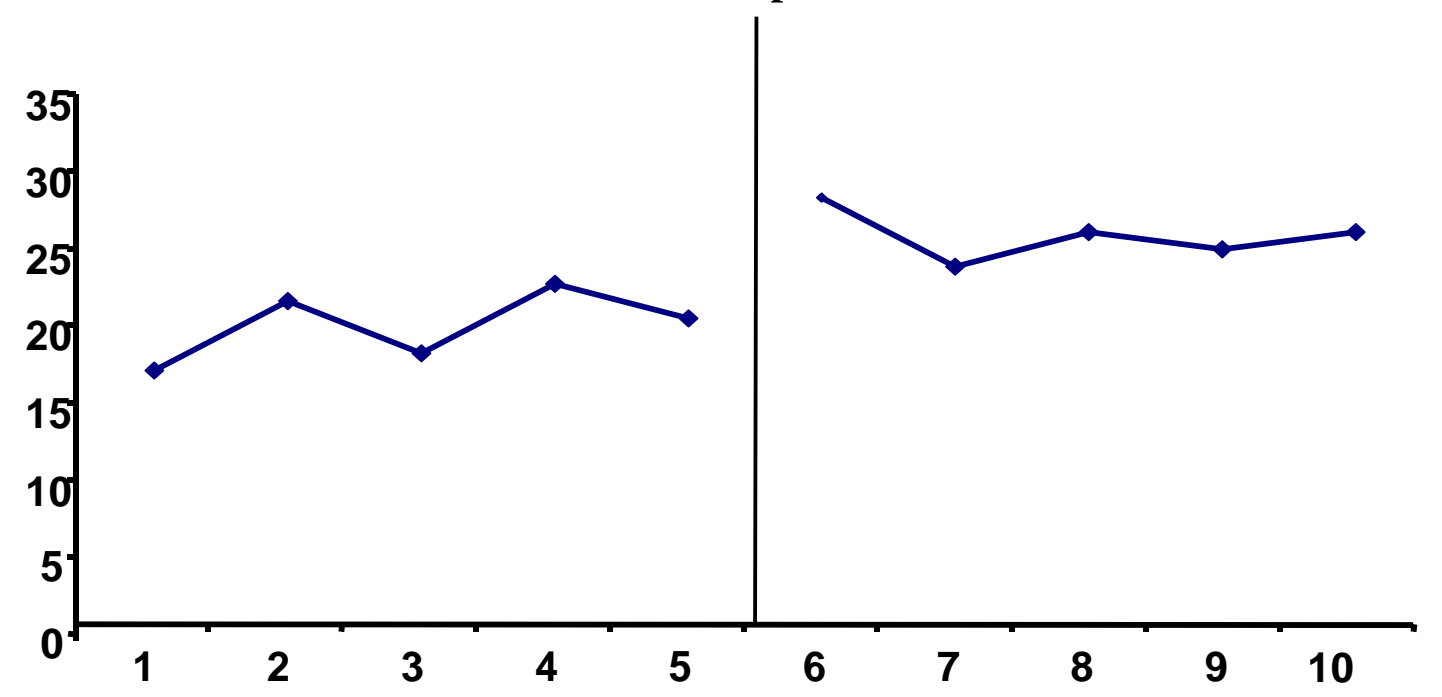




\section{Participant 1}

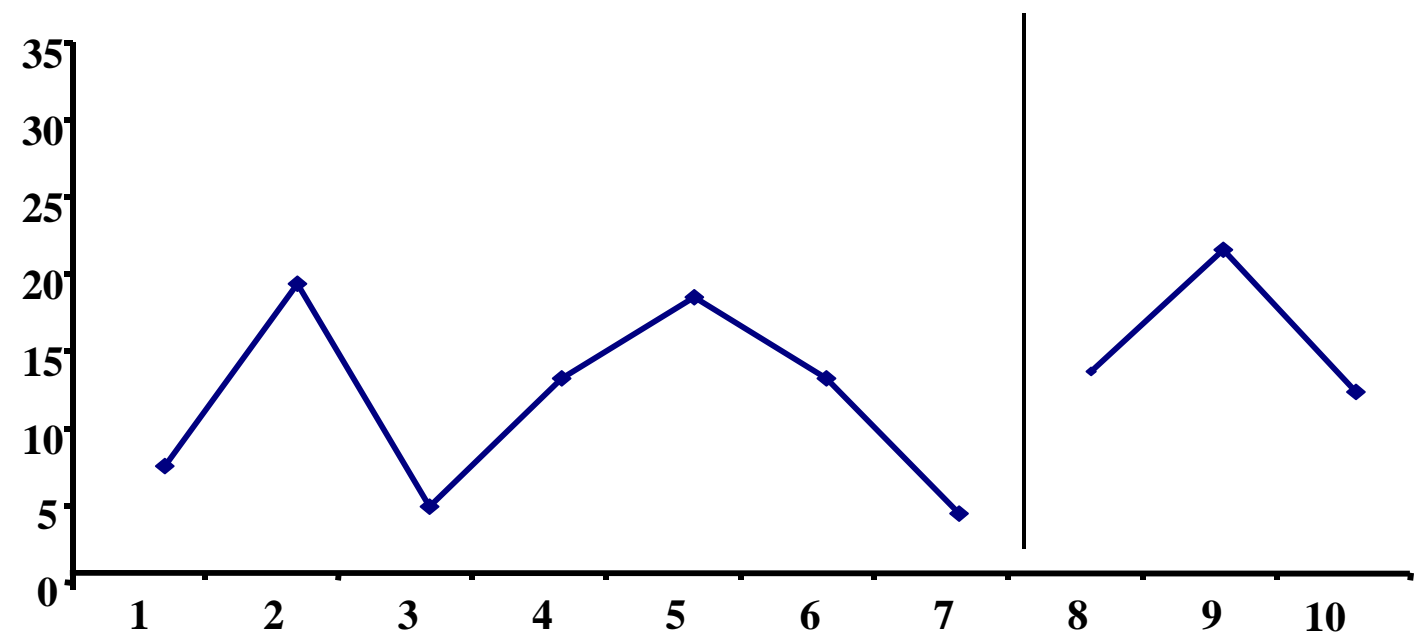

Participant 2

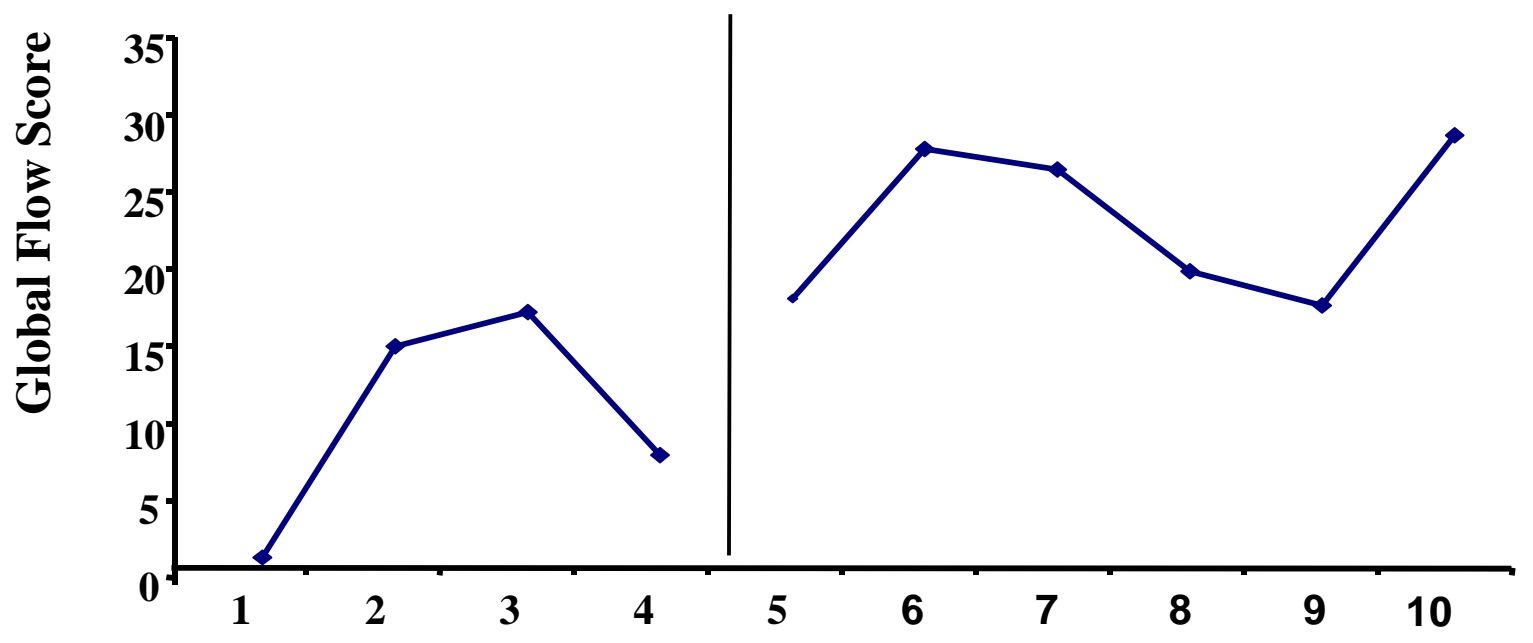

Participant 3

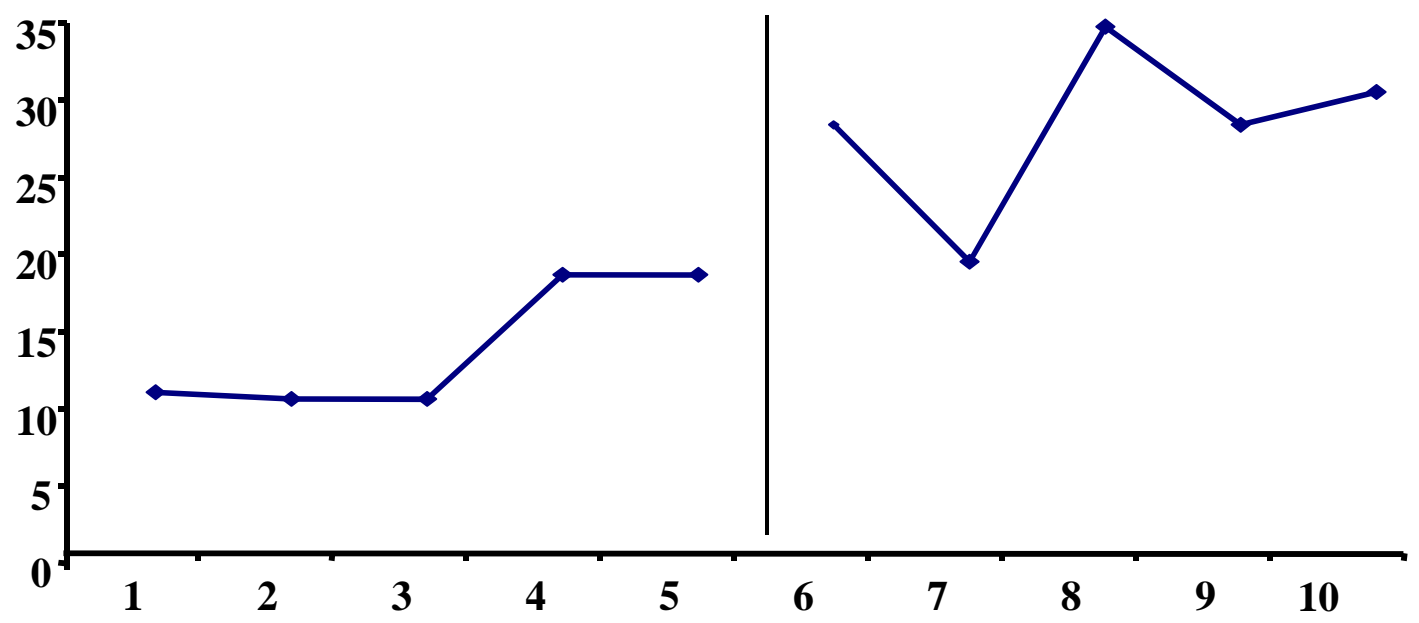

TRIALS 